\title{
A MULTI-OBJECTIVE DISPLACEMENT-BASED DESIGN PROCEDURE OF VISCOUS AND HYSTERETIC DAMPED BRACES FOR THE SEISMIC PROTECTION OF RC BUILDINGS
}

\author{
Fabio Mazza ${ }^{1}$ and Carlo Pasceri ${ }^{2}$ \\ ${ }^{1}$ Dipartimento di Ingegneria Civile, Università della Calabria \\ 87036, Rende (Cosenza), Italy \\ e-mail: fabio.mazza@unical.it \\ ${ }^{2}$ Dipartimento di Ingegneria Civile, Università della Calabria \\ 87036, Rende (Cosenza), Italy \\ e-mail: carlopasceri@libero.it
}

\begin{abstract}
The use of hysteretic damped braces (HYDBs) is an effective and low-cost solution for the seismic retrofitting of reinforced concrete (RC) framed structures. However, notable damage to nonstructural elements can be observed at the serviceability design earthquake (SDE), when too high activation forces of the HYDBs are designed in order to attain structural safety (SS) performance level at the basic (BDE) and/or maximum considered (MCE) earthquakes. On the other hand, HYDBs designed at the immediate occupancy (IO) performance level prevent nonstructural damage of MIs under SDE but may collapse and/or induce structural damage for high intensity seismic loads, due to their early activation which renders them unable to develop large energy dissipation. Aim of this work is the proposal of a multiobjective displacement-based design procedure, where viscous damped braces (VDBS) and $H Y D B s$ calculated for IO at the SDE are combined with HYDBs ensuring SS at the MCE. A six-storey $R C$ framed structure, representative of the residential building stock in Italy prior to the 2008-2018 code changes, is to be retrofitted in a high risk-seismic region supposing that is preliminarily designed in L'Aquila (Italy) for moderate seismic loads. The OpenSEES platform is considered for the nonlinear dynamic analysis of the original and retrofitted structures. RC frame members are modelled with lumped plasticity elements while the shear behaviour of the beam-column joints is modelled by means of a scissor model. Masonry infills uniformly distributed in elevation are modelled with a simplified diagonal pin-jointed strut model taking into account the in-plane failure modes. HYDBs are modelled with truss elements characterized by a bilinear force-displacement law, without considering the flexibility of the supports, while nonlinear force-velocity law is considered for VDBs. Nonlinear dynamic analysis is carried out considering three stripes of real records, corresponding to the SDE, $B D E$ and $M C E$ seismic levels assumed in the current Italian code.
\end{abstract}

Keywords: RC Framed Buildings, Dual Hysteretic-Viscous Damped Braces, Dual Hysteretic-Hysteretic Damped Braces, Two-Level Displacement-Based Design Procedure. 


\section{INTRODUCTION}

The use of hysteretic damped braces (HYDBs), based on a plastic deformation mechanism (e.g. axial, bending, shear, torsion) or a combination of some of them, represents an effective and low-cost solution for the seismic retrofitting of reinforced concrete (RC) framed structures [1]. However, notable damage to non-structural elements (e.g. masonry infills, false ceilings and suspended piping) can be observed at the serviceability design earthquake (SDE), when too high activation forces of the HYDBs are considered in order to improve structural performance level at the basic (BDE) and maximum considered (MCE) earthquakes $[2,3]$. To overcome this problem, dampers working as fuses can be inserted as sacrificial elements in order to prevent damage of non-structural elements [4], by means of an in-parallel combination of different typologies of dampers $[5,6]$, or alternatively damping and stiffness properties of dampers arranging in-series minor and major cores can be modulated to different seismic intensity levels [7]. A multi-objective design procedure is proposed in the present work, where viscous (VDBs) and hysteretic (HYDBs) damped braces calculated for immediate occupancy (IO), at SDE, are combined with HYDBs ensuring structural safety (SS), at MCE. To this end, a displacement-based design procedure already proposed in previous works [8-10] is applied, also including the loss of capacity of the existing structure due to previous seismic damage [11-12].

A six-storey RC framed building, representative of the Italian residential housing stock during the 1990s in a medium-risk seismic zone, is assumed as test structure for the numerical investigation [13]. This structure is supposed to be retrofitted by inserting HYDBs and VDBs to attain IO (e.g. no damage to masonry infills, MIs, at SDE) and SS (e.g. limited damage to structural elements at BDE and collapse prevention of HYDBs at MCE) performance levels imposed by current Italian seismic code (NTC18) in a high-risk seismic zone [14]. Specifically, five structural arrangements of damped braces are compared: only HYDBs designed at MCE; in-parallel combination of VDBs and HYDBs designed at SDE and MCE, respectively, possibly with gap-hook elements acting in series with the HYDBs so as to delay their activation at SDE; in-parallel and in-series combinations of small and large HYDBs designed at SDE and MCE, respectively, without and with a gap-hook element positioned in parallel with the small HYDBs, so as to stop their deformation at MCE. Nonlinear dynamic multi-stripe analyses of the original and retrofitted structures are carried out with the OpenSees code [15], considering three different set of records selected and scaled in line with SDE, BDE and MCE intensity levels provided by NTC18 [16]. Brittle and failure mechanisms of the original structure are modelled, considering: a lumped plasticity model for RC frame members, with flexure- or shear-controlled moment-chord rotation at the critical end sections; a scissor model with rigid offsets for shear behaviour of the beam-column joints; a diagonal pin-jointed strut model for MIs, taking into account their in-plane failure modes.

\section{DISPLACEMENT-BASED DESIGN PROCEDURE OF DAMPED BRACES}

A multistep iterative Displacement-Based Design (DBD) procedure of HYDBs, proposed in previous works [8-10], is extended for the seismic retrofitting of RC framed structures with dual hysteretic-viscous and hysteretic-hysteretic damped braces designed at both SDE and MCE, with or without a gap-hook element to avoid activation of small and large dampers at MCE and SDE, respectively.

As first step, the pushover curve of the original structure $(\mathrm{V}-\mathrm{d})$ is converted to that of an equivalent SDOF system $\left(\mathrm{V}^{*}-\mathrm{d}^{*}\right)$ and a piecewise linear fit of the initial backbone curve is determined by an ensemble of $\mathrm{N}$ pairs of bilinear elastic-perfectly plastic and elastic-softening damage laws [12]. Then, the damaged backbone curve that envelopes the hysteretic behaviour 
of the equivalent SDOF system subjected to seismic loads is evaluated from nonlinear dynamic analysis of the combined plastic-damage hysteretic model. The monotonic and cyclic deterioration of plastic and damage mechanisms is described by a damage loading index $\Psi$ [11], expressed as function of an ever-increasing curve whose shape depends on a degradation rate parameter (e.g. $\varepsilon=0.5$ ). A weighting coefficient (e.g. $\left.\mathrm{C}_{\mathrm{wc}}=0.25\right)$ distinguishes the effect of displacements less or greater than the previous maximum values $\left(\mathrm{d}^{*}{ }_{\max }\right)$ in the same loading direction, while a damage coupling parameter (e.g. $\mathrm{C}_{\mathrm{cd}}=0.5$ ) accounts for the influence of the energy dissipation under positive and negative forces on negative and positive values of the loading variable. Finally, the hysteretic energy dissipation of the degraded frame $\left(\xi_{\mathrm{h}, \mathrm{F}}\right)$ and the effective stiffness $\left(\mathrm{K}_{\mathrm{e}, \mathrm{F}}\right)$ related to the performance displacement $\left(\mathrm{d}_{\mathrm{p}}^{*}\right)$ can be evaluated, while elastic viscous damping of the framed structure (e.g. $\xi_{\mathrm{v}, \mathrm{F}}=5 \%$ ) can be assigned (Figure 1a).

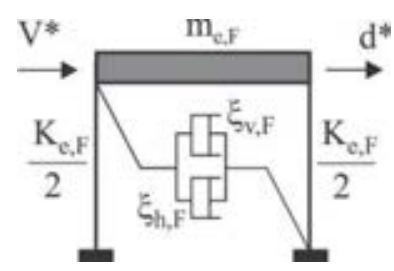

(a)

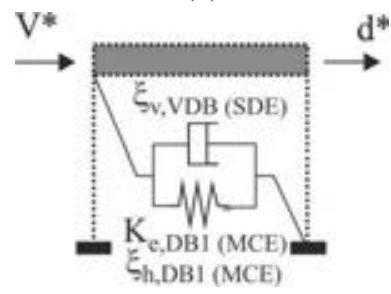

(d)

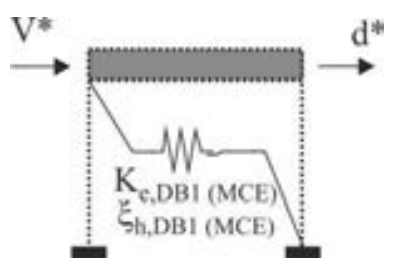

(b)

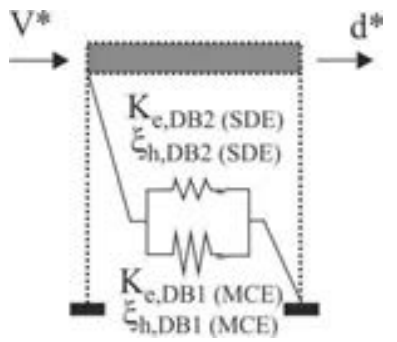

(e)

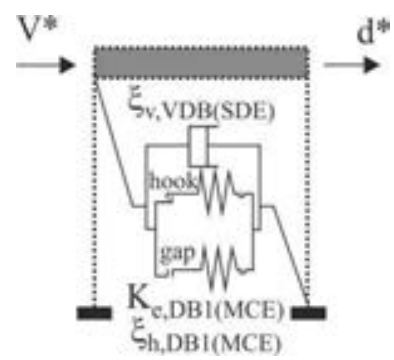

(c)

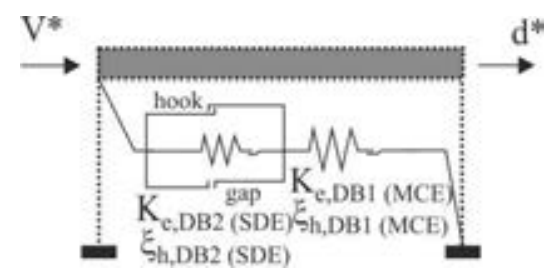

(f)

Figure 1. SDOF systems equivalent to the original structure (a), hysteretic (b) and dual hysteretic-viscous (c, d) and hysteretic-hysteretic (e, f) damped braces.

In order to design hysteretic (Figure 1b) and dual hysteretic-viscous (Figures 1c,d) and hysteretic-hysteretic (Figures 1e,f) damped braces at MCE, an iterative procedure is implemented in the acceleration-displacement response spectrum (ADRS) shown in Figure 2, where the bilinear capacity curve of the original structure is represented with a solid blue line. An initial value of the equivalent viscous damping ratio of the damped braced frame (i.e. $\left.\xi_{\mathrm{e}, \mathrm{DBF}}>\xi_{\mathrm{v}, \mathrm{F}}+\xi_{\mathrm{h}, \mathrm{F}}\right)$ is tentatively assumed at the selected performance displacement $\left(\mathrm{d}_{\mathrm{p}}^{*}\right)$ corresponding to MCE, starting from 5\% damped spectrum (solid black line). Then, effective vibration period $\left(\mathrm{T}_{\mathrm{e}, \mathrm{DBF}, \mathrm{MCE}}\right)$ of the retrofitted structure is determined on the reduced ADRS spectrum (dashed black line), starting from the trial performance point corresponding to the target displacement value, so allowing the calculation of effective stiffness $\mathrm{K}_{\mathrm{e}, \mathrm{DB}}\left(=\mathrm{K}_{\mathrm{e}, \mathrm{DBF}}-\mathrm{K}_{\mathrm{e}, \mathrm{F}}\right)$ of the equivalent $\mathrm{DB}$ at $\mathrm{MCE}$ (i.e. DB1). Once ductility demand $\left(\mu_{\mathrm{DB} 1}\right)$ and hardening ratio $\left(\mathrm{r}_{\mathrm{DB} 1}\right)$ of DB1 are assigned, it is possible to calculate the bilinear capacity curve of the damped brace (solid red line in Figure 2 ) and its viscous damping ( $\left.\xi_{\mathrm{h}, \mathrm{DB} 1}\right)$ equivalent to the hysteretic energy dissipation:

$$
\xi_{h, D B 1}^{(M C E)}(\%)=63.7 \frac{\left(\mu_{D B 1}-1\right) \cdot\left(1-r_{D B 1}\right)}{\mu_{D B 1}\left[1+r_{D B 1} \cdot\left(\mu_{D B 1}-1\right)\right]}
$$


Finally, an updated value of the equivalent viscous damping of the retrofitted structure can be evaluated, being $\mathrm{V}_{\mathrm{p}, \mathrm{F}}^{*}$ and $\mathrm{V}_{\mathrm{p}, \mathrm{DB} 1}^{*}$ strength values of the original frame and damped brace at $\mathrm{d}_{\mathrm{p}}^{*}$, respectively:

$$
\xi_{e, D B F}^{(M C E)}(\%)=\xi_{v, F}+\frac{\xi_{h, F}^{(M C E)} \cdot V_{p, F}^{*(M C E)}+\xi_{h, D B 1}^{(M C E)} \cdot V_{p, D B 1}^{*(M C E)}}{V_{p, F}^{*(M C E)}+V_{p, D B 1}^{*(M C E)}}
$$

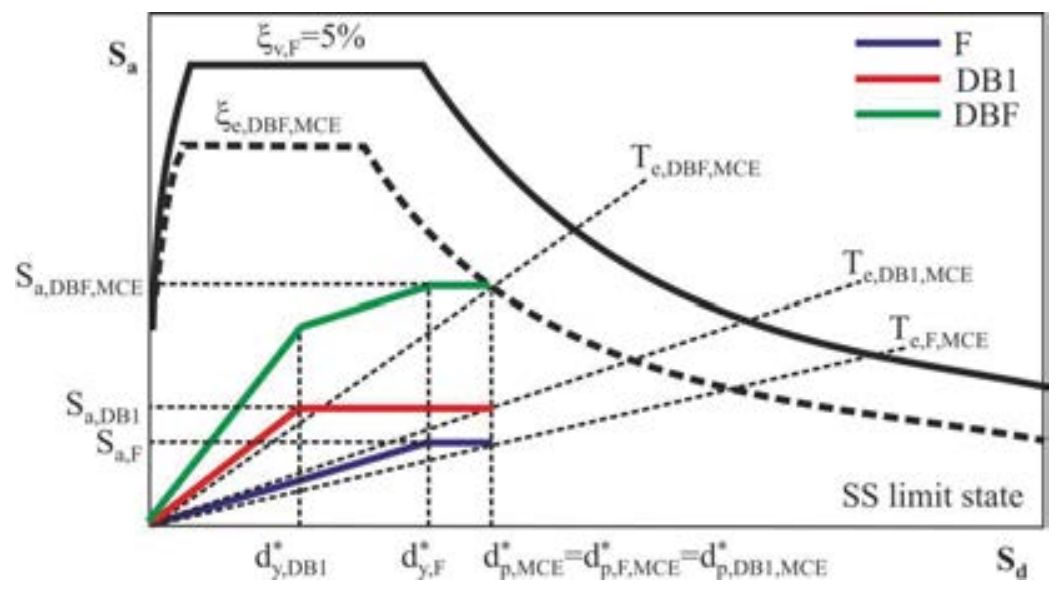

Figure 2. Design procedure of the hysteretic and dual hysteretic-viscous and hysteretic-hysteretic damped braces in the acceleration-displacement response spectrum at MCE.

In a similar way, viscous (Figures 1c,d) and hysteretic (Figure 1e) dampers at SDE, in parallel with the hysteretic damped brace previously designed at MCE (DB1), may be evaluated with an iterative process in the ADRS corresponding to SDE (Figure 3). At this point, the admitted target displacement $\left(\mathrm{d}_{\mathrm{p}, \mathrm{SDE}}^{*}\right)$ and first equivalent viscous damping ratio $\left(\xi_{\mathrm{e}, \mathrm{DBF}, \mathrm{SDE}}\right)$ of the retrofitted structure will be considered in the evaluation of effective vibration period $\left(T_{\mathrm{e}, \mathrm{DBF}, \mathrm{SDE}}\right)$ corresponding to dashed black line in Figure 3. Keeping in mind that the effective stiffness of DB1 is already known from the bilinear capacity curve corresponding to $\mathrm{d}_{\mathrm{p}, \mathrm{SDE}}^{*}$, the effective stiffness $\left(\mathrm{K}_{\mathrm{e}, \mathrm{DB} 1}\right)$ of the additional damper (e.g. hysteretic in Figure 1e) for small deformation (DB2) can be determined by a simple subtraction $\left(\mathrm{K}_{\mathrm{e}, \mathrm{DB} 2}=\mathrm{K}_{\mathrm{e}, \mathrm{DBF}}-\mathrm{K}_{\mathrm{e}, \mathrm{DB} 1}-\mathrm{K}_{\mathrm{e}, \mathrm{F}}\right)$. It is worth highlighting that contribution of DB1 disappears when it is attached in series to a gap-hook element (Figure 1c), so avoiding its action at SDE.

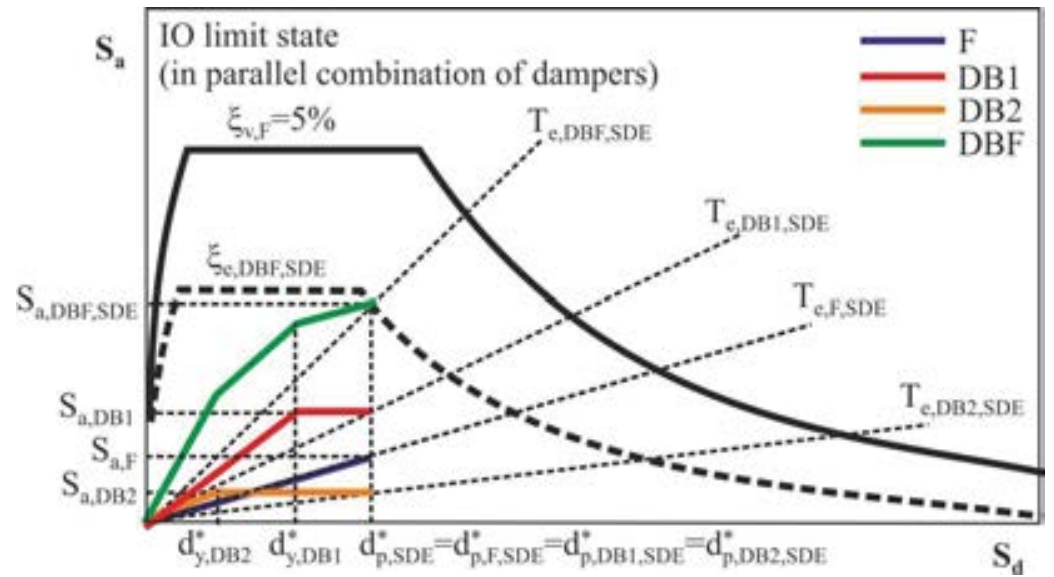

Figure 3. Design procedure of the in-parallel hysteretic-viscous and hysteretic-hysteretic damped braces in the acceleration-displacement response spectrum at SDE.

Once viscous damping equivalent to the hysteretic energy dissipation of DB2 is evaluated $\left(\xi_{\mathrm{h}, \mathrm{DB} 2}\right)$ as function of the assigned values of $\mu_{\mathrm{DB} 2}$ and $\mathrm{r}_{\mathrm{DB} 2}$ (see Equation (1)), an updated val- 
ue of the equivalent viscous damping can be obtained for the retrofitted structure

$$
\xi_{e, D B F}^{(S D E)}(\%)=\xi_{v, F}+\frac{\xi_{h, F}^{(S D E)} \cdot V_{p, F}^{*(S D E)}+\xi_{h, D B 1}^{(S D E)} \cdot V_{p, D B 1}^{*(S D E)}+\xi_{h, D B 2}^{(S D E)} \cdot V_{p, D B 2}^{*(S D E)}}{V_{p, F}^{*(S D E)}+V_{p, D B 1}^{*(S D E)}+V_{p, D B 2}^{*(S D E)}}
$$

depending on strength values, at the performance displacement $\mathrm{d}_{\mathrm{p}, \mathrm{SDE}}{ }^{\mathrm{N}}$, for the original frame $\left(\mathrm{V}_{\mathrm{p}, \mathrm{F}}^{*}\right)$ and hysteretic DB1 $\left(\mathrm{V}_{\mathrm{p}, \mathrm{DB} 1}^{*}\right)$ and DB2 $\left(\mathrm{V}_{\mathrm{p}, \mathrm{DB} 2}^{*}\right)$. Moreover, the expression

$$
\xi_{e, D B F}^{(S D E)}(\%)=\xi_{v, F}+\xi_{V D B}^{(S D E)}+\frac{\xi_{h, F}^{(S D E)} \cdot V_{p, F}^{*(S D E)}+\xi_{h, D B 1}^{(S D E)} \cdot V_{p, D B 1}^{*(S D E)}}{V_{p, F}^{*(S D E)}+V_{p, D B 1}^{*(S D E)}}
$$

corresponds to viscous damped brace (VDB) at small deformation combined with DB1 at large deformation (Figure 1d), with the further simplification

$$
\xi_{e, D B F}^{(S D E)}(\%)=\xi_{v, F}+\xi_{V D B}^{(S D E)}+\xi_{h, F}^{(S D E)}
$$

when DB1 is also combined with a gap-hook mechanism (Figure 1c).

As an alternative, in-series combination of hysteretic-hysteretic dampers (Figure 1f) may be considered adopting the iterative design process described in the ADRS corresponding to SDE (Figure 4), where the gap-hook mechanism acts as a very stiff end-stroke stopper that limits deformations of DB2 at the SDE threshold while ensuring that the energy dissipation at MCE is entrusted to DB1. This time, a starting value of the displacement of DB1 $\left(\mathrm{d}^{*}{ }_{\mathrm{p}, \mathrm{DB} 1}\right)$ is tentatively assumed at the selected performance displacement $\left(\mathrm{d}^{*} \mathrm{p}\right)$ at SDE, such to obtain as difference the displacement of DB2 $\left(\mathrm{d}_{\mathrm{p}, \mathrm{DB} 2}^{*}=\mathrm{d}_{\mathrm{p}}{ }_{\mathrm{p}}-\mathrm{d}_{\mathrm{p}, \mathrm{DB} 1}\right)^{*}$. Effective stiffness of both dampers $(\mathrm{DB} 1+\mathrm{DB} 2)$ can be evaluated as function of the strength $\mathrm{V}_{\mathrm{p}, \mathrm{DB} 1}^{*}\left(=\mathrm{V}_{\mathrm{p}, \mathrm{DB} 2}^{*}\right)$ corresponding to $\mathrm{d}_{\mathrm{p}, \mathrm{DB} 1}^{*}$

$$
K_{e, D B 1}^{(S D E)}=\frac{V_{p, D B 1}^{*}(S D E)}{d_{p, D B 1}^{*}(S D E)} ; K_{e, D B 2}^{(S D E)}=\frac{V_{p, D B 1}^{*(S D E)}}{d_{p, D B 2}^{*}(S D E)}
$$

and from these ones the total stiffness

$$
K_{e, D B F}^{(S D E)}=K_{e, F}^{(S D E)}+\frac{K_{e, D B 1}^{(S D E)} \cdot K_{e, D B 2}^{(S D E)}}{K_{e, D B 1}^{(S D E)}+K_{e, D B 2}^{(S D E)}}
$$

and effective period $\left(\mathrm{T}_{\mathrm{e}, \mathrm{DBF}, \mathrm{SDE}}\right)$ of the retrofitted structure are derived. In order to determine the corresponding equivalent viscous damping ratio $\xi_{\mathrm{e}, \mathrm{DBF}, \mathrm{SDE}}$, curve passing through the trial performance point is drawn in Figure 4 (solid green line).

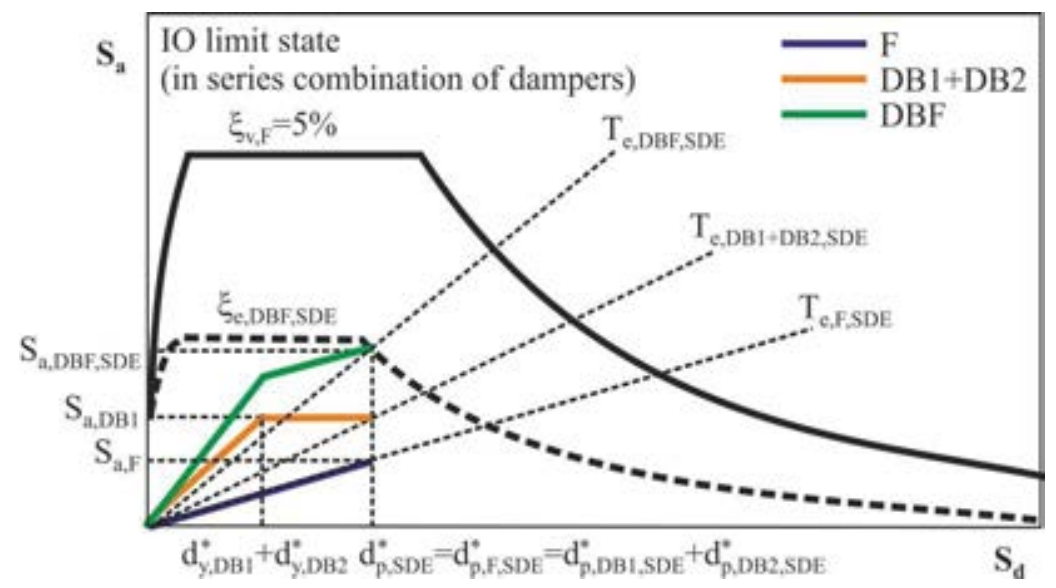

Figure 4. Design procedure of the in-series hysteretic-hysteretic damped braces in the acceleration-displacement response spectrum at SDE. 
On the other hand, equivalent viscous damping ratio is analytically evaluated with the expression

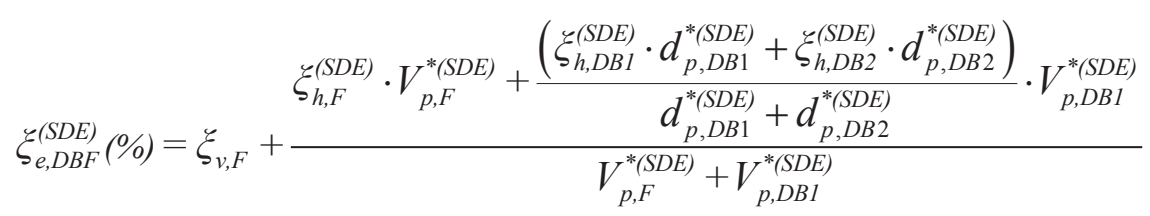

and an iterative process is triggered until graphical and analytical values are the same.

Finally, vertical distributions of the (elastic) lateral stiffness of the HYDBs and damping coefficients of the nonlinear VDBs are evaluated proportionally to the interstorey drift and design storey shear of the original structure, respectively. Further information is contained in previous papers $[8,17]$, which complete the necessary detailing of the work.

\section{ORIGINAL AND RETROFITTED TEST STRUCTURES}

A six-storey RC framed structure (Figure 5a), representative of the residential buildings constructed in Italy during the 1990s, is selected from the RINTC project [13]. It is located in L'Aquila and designed as bare frame for a medium-risk zone, in line with provisions of the Italian code DM86 [18], assuming concrete with cylindrical compressive strength of $25 \mathrm{MPa}$ and steel reinforcement with yield strength of $430 \mathrm{MPa}$. Columns with rectangular crosssection, oriented as shown in Figure 5b, are tapered along the height, considering: $0,3 \times 0,6 \mathrm{~m}^{2}$ at the first two levels; $0,30 \times 0,5 \mathrm{~m}^{2}$ at the third and fourth levels; $0,3 \times 0,4 \mathrm{~m}^{2}$ at the fifth and roof levels. The structure has deep beams along the perimeter and in the knee configuration of the staircase, with cross section $0,3 \times 0,6 \mathrm{~m}^{2}$ at the first two levels and $0,3 \times 0,5 \mathrm{~m}^{2}$ at the other four levels, while flat beams are considered for all internal frames, with cross-section $0,6 \times$ $0,25 \mathrm{~m}^{2}$ and $0,8 \times 0,25 \mathrm{~m}^{2}$ (the latest marked with an asterisk in Figure $5 \mathrm{~b}$ ). Masonry infills with a double leaf $(0,08 \mathrm{~m}$, external layer, and $0,12 \mathrm{~m}$, internal layer) of hollow clay bricks are uniformly distributed along the height, with a percentage of openings depending on the inplan architectural layout: i.e. 0\%, MI.B in brown; 22\%, MI.Y in yellow; 40\%, MI.O in orange; $100 \%$, MI.G in green. Further details can be found in [13].

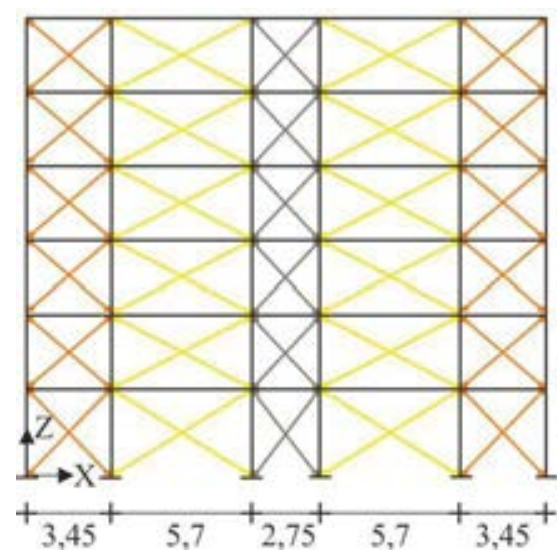

(a)

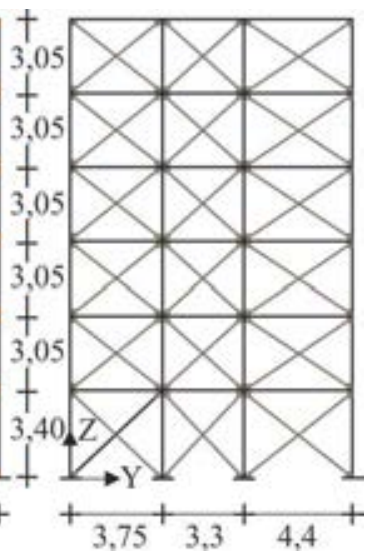

Figure 5. Original test structure (unit in $\mathrm{m}$ ).

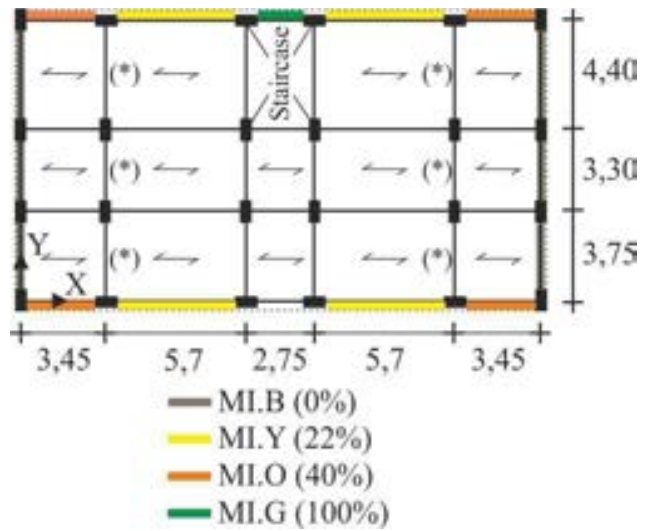

(b)

The seismic retrofitting of the original test structure is carried out by the insertion of chevron damped braces, with vertical distribution and in-plan arrangement shown in Figures 6a and $6 \mathrm{~b}$, respectively. Five structural configurations of damped braces are compared: i.e. HYDBs designed at MCE (Figure 6b); two in-parallel combinations of VDBs and HYDBs 
designed at SDE and MCE, respectively, with (Figure 6c) and without (Figure 6d) gap-hook elements attached in series with HYDBs; in-parallel and in-series combinations of small and large HYDBs designed at SDE and MCE, respectively, without (Figure 6e) and with (Figure 6f) gap-hook elements attached in parallel with the small HYDBs. The deformability of the supporting chevron steel braces is not considered (i.e. $\mathrm{K}_{B} \rightarrow \infty$ ), so that lateral stiffnesses of the HYDB $\left(\mathrm{K}_{\mathrm{DB}}\right)$ and HYD $\left(\mathrm{K}_{\mathrm{D}}\right)$ are assumed equal; this is also for the corresponding stiffness hardening ratios (i.e. $\mathrm{r}_{\mathrm{DB}}=\mathrm{r}_{\mathrm{D}}$ ). With regard to the $\mathrm{VDB}$, the force developed in the damper is function of a damping exponent $\beta=0.7$, which corresponds to nonlinear viscous property.

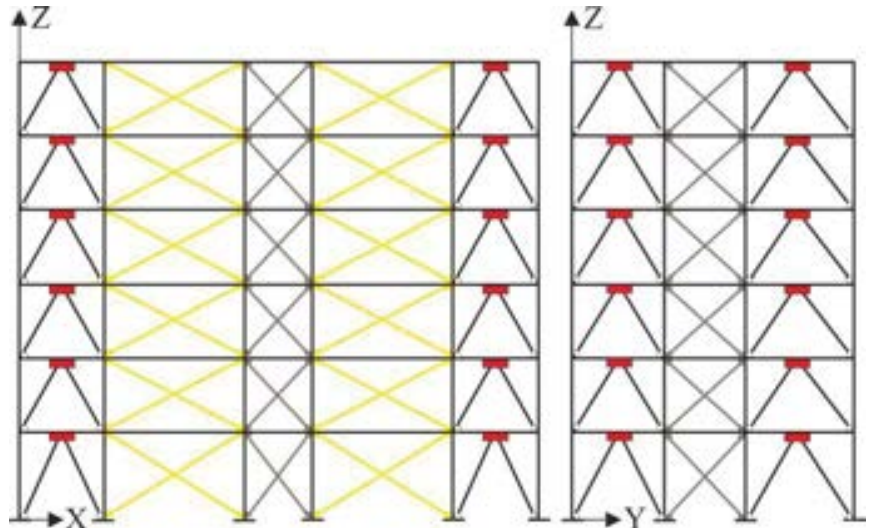

(a) Elevation.

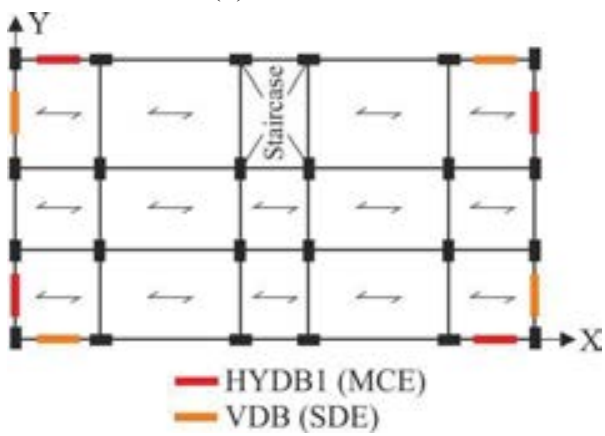

(c) In-parallel combination of HYDB1 and VDB, with a gap-hook element in series with HYDB1.

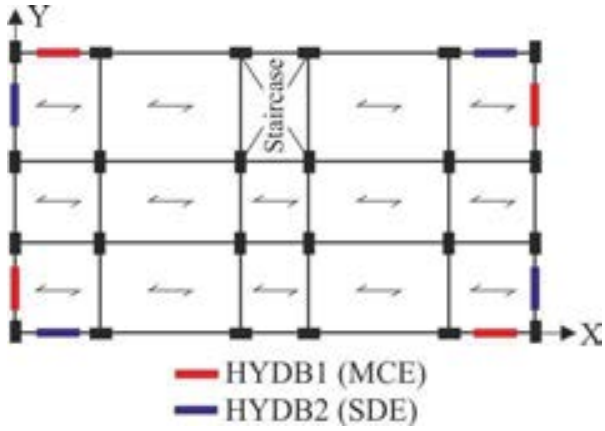

(e) In-parallel combination of HYDB1 and HYDB2, without a gap-hook element in parallel with HYDB2.

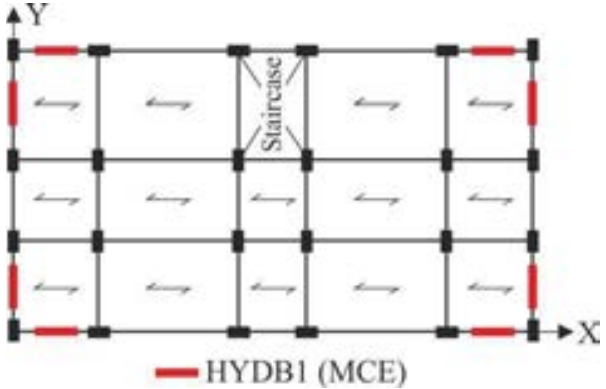

(b) Plan.

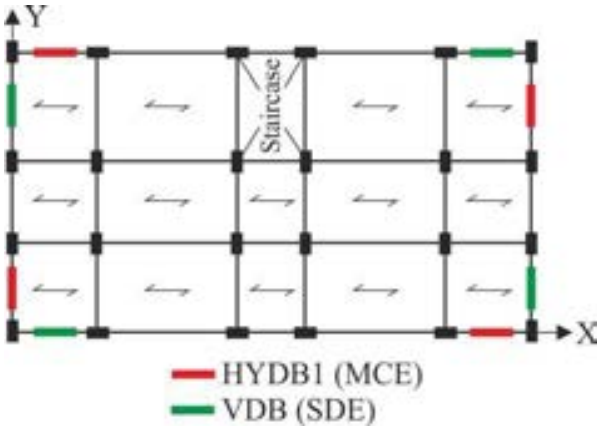

(d) In-parallel combination of HYDB1 and VDB, without a gap-hook element in series with HYDB1.

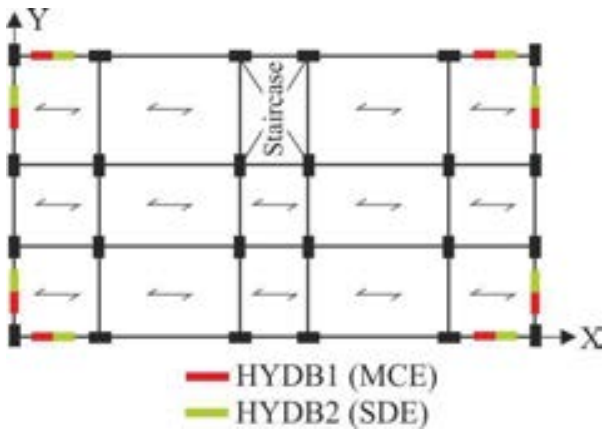

(f) In-series combination of HYDB 1 and HYDB2, with a gap-hook element in parallel with HYDB2.

Figure 6. Retrofitted test structures.

Thirteen structural layouts are obtained combining above described five configurations of damped braces with: three ultimate performance levels in terms of top displacement (i.e. 
$\mathrm{d}_{\mathrm{p}, \mathrm{X}, \mathrm{MCE}}=0,093 \mathrm{~m}, 0,14 \mathrm{~m}$ and $0.184 \mathrm{~m}$ and $\mathrm{d}_{\mathrm{p}, \mathrm{Y}, \mathrm{MCE}}=0,093 \mathrm{~m}$ and $\left.0,14 \mathrm{~m}\right)$, associated with different structural damage scenarios in terms of inter-storey drift ratio (i.e. $\Delta_{\mathrm{X}} / \mathrm{h}=0.5 \%, 0.75 \%$ and $1 \%$ and $\Delta_{\mathrm{Y}} / \mathrm{h}=0.5 \%$ and $0.75 \%$ ); one serviceability target displacement (i.e. $\mathrm{d}_{\mathrm{p}, \mathrm{X}, \mathrm{SDE}}=0,019$ $\mathrm{m}$ and $\mathrm{d}_{\mathrm{p}, \mathrm{Y}, \mathrm{SDE}}=0,042 \mathrm{~m}$ ), corresponding to the attainment of the minimum value of peak lateral strength in the masonry infills of each storey, so preventing non-structural damage. Constant design values of damper ductility (i.e. $\mu_{\mathrm{D}}=5$ ) and hardening ratios (i.e. $\mathrm{r}_{\mathrm{F}}=0 \%$ and $\mathrm{r}_{\mathrm{D}}=3 \%$ ) are also assumed, except for the in-series arrangement of HYDBs. Main parameters of the equivalent damped braces along the in-plan principal directions are reported in Tables 1-5, with reference to: HYDB1 at MCE (Table 1); in-parallel combination of HYDB1 and VDB at SDE (Table 2); VDB at SDE (Table 3); in-parallel combination of HYDB1 and HYDB2 at SDE (Table 4); in-series combination of HYDB1 and HYDB2 at SDE (Table 5).

\begin{tabular}{|c|c|c|c|c|c|c|c|c|c|c|c|c|}
\hline Dir. & $\mathrm{d}_{\mathrm{p}, \mathrm{MCE}}^{*}$ & $\mathrm{~d}_{\mathrm{y}, \mathrm{DB} 1}^{*}$ & $\mathrm{~K}_{\mathrm{e}, \mathrm{F}}$ & $\mathrm{K}_{\mathrm{e}, \mathrm{DB} 1}$ & $\mathrm{~V}_{\mathrm{p}, \mathrm{F}}^{*}$ & $\mathrm{~V}_{\mathrm{p}, \mathrm{DB} 1}^{*}$ & $\mathrm{~T}_{\mathrm{e}, \mathrm{F}}$ & $\mathrm{T}_{\mathrm{e}, \mathrm{DBF}}$ & $\xi_{\mathrm{v}, \mathrm{F}}$ & $\xi_{\mathrm{h}, \mathrm{F}}$ & $\xi_{\mathrm{h}, \mathrm{DBB}}$ & $\xi_{\mathrm{e}, \mathrm{DBF}}$ \\
\hline \multirow{3}{*}{$X$} & 0,072 & 0,014 & 23290 & 14953 & 1666 & 1069 & 1,31 & 1,03 & 5 & 12,00 & 44,13 & 29,56 \\
\hline & 0,107 & 0,022 & 7877 & 7308 & 847 & 785 & 2,26 & 1,63 & 5 & 14,14 & 44,13 & 33,58 \\
\hline & 0,143 & 0,029 & 2364 & 4998 & 338 & 715 & 4,13 & 2,34 & 5 & 15,34 & 44,13 & 39,84 \\
\hline \multirow{3}{*}{ Y } & 0,071 & 0,014 & 26465 & 13737 & 1875 & 973 & 1,22 & 0,99 & 5 & 11,73 & 44,13 & 27,80 \\
\hline & 0,106 & 0,021 & 969 & 10349 & 103 & 1101 & 6,37 & 1,87 & 5 & 14,90 & 44,13 & 46,63 \\
\hline & 0,106 & 0,021 & 969 & 10349 & 103 & 1101 & 6,37 & $\begin{array}{ll}1,87 \\
\end{array}$ & 5 & 14,90 & 44,13 & 46,63 \\
\hline
\end{tabular}

Table 1. Properties of the SDOF system equivalent to the DBF at MCE: HYDB1 (units in $\mathrm{m}, \mathrm{kN}$ and $\mathrm{s}$ ).

\begin{tabular}{|c|c|c|c|c|c|c|c|c|}
\hline Dir. & $\mathrm{d}_{\mathrm{p}, \mathrm{SDE}}^{*}$ & $\mathrm{~K}_{\mathrm{e}, \mathrm{F}}$ & $\mathrm{V}_{\mathrm{p}, \mathrm{F}}$ & $\mathrm{T}_{\mathrm{e}, \mathrm{F}}$ & $\mathrm{T}_{\mathrm{e}, \mathrm{DBF}}$ & $\xi_{\mathrm{v}, \mathrm{F}}$ & $\xi_{\mathrm{VDB}}$ & $\xi_{\mathrm{e}, \mathrm{DBF}}$ \\
\hline $\mathrm{X}$ & 0,015 & 57274 & 851 & 0,838 & 0,838 & 5 & 42,37 & 47,37 \\
\hline $\mathrm{Y}$ & 0,032 & 62923 & 1996,69 & 0,791 & 0,791 & 5 & 0,21 & 5,21 \\
\hline
\end{tabular}

Table 2. Properties of the SDOF system equivalent to the DBF at SDE: VDB (units in $\mathrm{m}, \mathrm{kN}$ and s).

\begin{tabular}{|c|c|c|c|c|c|c|c|c|c|c|c|}
\hline Dir. & $\mathrm{d}_{\mathrm{p}, \mathrm{MCE}}^{*}$ & $\mathrm{~d}_{\mathrm{p}, \mathrm{SDE}}^{*}$ & $\mathrm{~K}_{\mathrm{e}, \mathrm{F}}$ & $\mathrm{K}_{\mathrm{e}, \mathrm{DB} 1}$ & $\mathrm{~V}_{\mathrm{p}, \mathrm{F}}^{*}$ & $\mathrm{~V}_{\mathrm{p}, \mathrm{DB} 1}^{*}$ & $T_{\mathrm{e}, \mathrm{F}}$ & $\mathrm{T}_{\mathrm{e}, \mathrm{DBF}}$ & $\xi_{\mathrm{VDB}}$ & $\xi_{\mathrm{h}, \mathrm{DB} 1}$ & $\xi_{\mathrm{e}, \mathrm{DBF}}$ \\
\hline \multirow{3}{*}{ X } & 0,072 & \multirow{3}{*}{0,015} & \multirow{3}{*}{57273} & 28081 & \multirow{3}{*}{850} & 953 & \multirow{3}{*}{0,84} & 0,69 & 13,51 & 2,25 & 19,69 \\
\hline & 0,107 & & & 16375 & & 483 & & 0,74 & 23,40 & 0 & 28,40 \\
\hline & 0,143 & & & 14759 & & 331 & & 0,75 & 27,71 & 0 & 32,71 \\
\hline \multirow{3}{*}{ Y } & 0,071 & \multirow{3}{*}{0,032} & \multirow{3}{*}{62923} & 28405 & \multirow{3}{*}{1997} & 901 & \multirow{3}{*}{0,79} & 0,66 & 0 & 32,97 & 15,25 \\
\hline & 0,106 & & & 31382 & & 996 & & 0,65 & 0 & 20,04 & 11,67 \\
\hline & 0,106 & & & 31328 & & 996 & & 0,65 & 0 & 20,04 & 11,67 \\
\hline
\end{tabular}

Table 3. Properties of the SDOF system equivalent to the DBF at SDE: in parallel combination of HYDB1 and VDB (units in $\mathrm{m}, \mathrm{kN}$ and $\mathrm{s}$ ).

\begin{tabular}{|c|c|c|c|c|c|c|c|c|c|}
\hline Dir. & $\mathrm{d}_{\mathrm{p}, \mathrm{MCE}}$ & $\mathrm{d}^{*}{ }_{\mathrm{p}, \mathrm{SDE}}$ & $\mathrm{d}^{*}{ }_{\mathrm{y}, \mathrm{DB} 2}$ & $\mathrm{~K}_{\mathrm{e}, \mathrm{F}}$ & $\mathrm{K}_{\mathrm{e}, \mathrm{DB} 2}$ & $\mathrm{~K}_{\mathrm{e}, \mathrm{DB} 1}$ & $\mathrm{~V}_{\mathrm{p}, \mathrm{F}}$ & $\mathrm{V}_{\mathrm{p}, \mathrm{DB} 2}$ & $\mathrm{~V}_{\mathrm{p}, \mathrm{DB} 1}$ \\
\hline \multirow{3}{*}{ X } & 0,072 & \multirow{3}{*}{0,015} & 0,003 & \multirow{3}{*}{57273} & 30367 & 64398 & \multirow{3}{*}{850} & 451 & 956 \\
\hline & 0,107 & & 0,003 & & 38933 & 32499 & & 578 & 483 \\
\hline & 0,143 & & 0,003 & & 40814 & 22311 & & 606 & 331 \\
\hline \multirow{3}{*}{$\mathrm{Y}$} & 0,071 & \multirow{3}{*}{0,032} & 0 & \multirow{3}{*}{62923} & 0 & 31202 & \multirow{3}{*}{1997} & 0 & 990 \\
\hline & 0,106 & & 0 & & 0 & 22329 & & 0 & 709 \\
\hline & 0,106 & & 0 & & 0 & 22329 & & 0 & 709 \\
\hline Dir. & $\mathrm{d}_{\mathrm{p}, \mathrm{MCE}}$ & $\mathrm{d}_{\mathrm{p}, \mathrm{SDE}}$ & $T_{e, F}$ & $T_{e, \mathrm{DBF}}$ & $\xi_{\mathrm{v}, \mathrm{F}}$ & $\xi_{\mathrm{h}, \mathrm{DB} 2}$ & $\xi_{\mathrm{h}, \mathrm{DB} 1}$ & $\xi_{\mathrm{e}, \mathrm{DBF}}$ & \\
\hline \multirow{3}{*}{ X } & 0,072 & \multirow{3}{*}{0,015} & \multirow{3}{*}{0,84} & 0,51 & \multirow{3}{*}{5} & 44,13 & 2,25 & 14,76 & \\
\hline & 0,107 & & & 0,56 & & 44,13 & 0 & 18,35 & \\
\hline & 0,143 & & & 0,58 & & 44,13 & 0 & 19,96 & \\
\hline \multirow{3}{*}{$\mathrm{Y}$} & 0,071 & \multirow{3}{*}{0,032} & \multirow{3}{*}{0,79} & 0,65 & \multirow{3}{*}{5} & 0 & 32,73 & 15,85 & \\
\hline & 0,106 & & & 0,68 & & 0 & 19,65 & 10,15 & \\
\hline & 0,106 & & & 0,68 & & 0 & 19,65 & 10,15 & \\
\hline
\end{tabular}

Table 4. Properties of the SDOF system equivalent to the DBF at SDE: in parallel combination of HYDB1 HYDB2 (units in $\mathrm{m}, \mathrm{kN}$ and $\mathrm{s}$ ). 


\begin{tabular}{|c|c|c|c|c|c|c|c|c|c|c|}
\hline Dir. & $\mathrm{d}_{\mathrm{p}, \mathrm{MCE}}^{*}$ & $\mathrm{~d}_{\mathrm{p}, \mathrm{SDE}}^{*}$ & $\mathrm{~d}_{\mathrm{y}, \mathrm{DB} 2}^{*}$ & $\mathrm{~d}_{\mathrm{p}, \mathrm{DB} 2}^{*}$ & $\mathrm{~d}_{\mathrm{p}, \mathrm{DB} 1}^{*}$ & $\overline{\mathrm{K}_{\mathrm{e}, \mathrm{F}}}$ & $\mathrm{K}_{\mathrm{e}, \mathrm{DB} 2}$ & $\mathrm{~K}_{\mathrm{e}, \mathrm{DB} 1}$ & $\mathrm{~V}_{\mathrm{p}, \mathrm{F}}^{*}$ & $\mathrm{~V}_{\mathrm{p}, \mathrm{DB} 2}$ \\
\hline \multirow{3}{*}{$X$} & 0,072 & \multirow{3}{*}{0,015} & 0,003 & 0,0068 & 0,0082 & \multirow{3}{*}{57273} & 81971 & 68214 & \multirow{3}{*}{850} & 557 \\
\hline & 0,107 & & 0,003 & 0,0024 & 0,0127 & & 172000 & 32511 & & 413 \\
\hline & 0,143 & & 0,003 & 0.0016 & 0.0130 & & 180333 & 22272 & & 289 \\
\hline \multirow{3}{*}{$\mathrm{Y}$} & 0,071 & \multirow{3}{*}{0,032} & - & - & - & \multirow{3}{*}{62923} & - & 31202 & \multirow{3}{*}{1997} & - \\
\hline & 0,106 & & - & - & - & & - & 22329 & & - \\
\hline & 0,106 & & - & - & - & & - & 22329 & & - \\
\hline Dir. & $\mathrm{d}_{\mathrm{p}, \mathrm{MCE}}^{*}$ & $\mathrm{~d}_{\mathrm{p}, \mathrm{SDE}}^{*}$ & $\mathrm{~V}_{\mathrm{p}, \mathrm{DB} 1}^{*}$ & $\mathrm{~T}_{\mathrm{e}, \mathrm{F}}$ & $\mathrm{T}_{\mathrm{e}, \mathrm{DBF}}$ & $\xi_{\mathrm{v}, \mathrm{F}}$ & $\xi_{\mathrm{h}, \mathrm{DB} 2}$ & $\xi_{\mathrm{h}, \mathrm{DB} 1}$ & $\xi_{\mathrm{e}, \mathrm{DBF}}$ & \\
\hline \multirow{3}{*}{$\mathrm{X}$} & 0,072 & \multirow{3}{*}{0,015} & 557 & \multirow{3}{*}{0,84} & 0,65 & \multirow{3}{*}{5} & 35,89 & 0 & 11,46 & \\
\hline & 0,107 & & 413 & & 0,69 & & 0 & 0 & 5 & \\
\hline & 0,143 & & 289 & & 0,72 & & 0 & 0 & 5 & \\
\hline \multirow{3}{*}{ Y } & 0,071 & \multirow{3}{*}{0,032} & 990 & \multirow{3}{*}{0,79} & 0,65 & \multirow{3}{*}{5} & - & 32,73 & 15,85 & \\
\hline & 0,106 & & 709 & & 0,68 & & - & 19,65 & 10,15 & \\
\hline & 0,106 & & 709 & & 0,68 & & - & 19,65 & 10,15 & \\
\hline
\end{tabular}

Table 5. Properties of the SDOF system equivalent to the DBF at SDE: in series combination of HYDB1 and HYDB2 (units in $\mathrm{m}, \mathrm{kN}$ and s).

\section{NUMERICAL RESULTS}

In this section, the effectiveness of the proposed multi-objective design procedure and the limitation of use of HYDBs, designed at MCE, in combination with HYDBs and VDBs, designed at SDE, are investigated on the five-storey RC building described in Section 2. Five structural arrangements of damped braces are considered in order to modulate effective damping and stiffness properties to assigned performance targets at the serviceability (e.g. protection of non-structural elements) and ultimate (e.g. upgrading up to full retrofitting of structural parts and collapse prevention of damped braces) limit states. Nonlinear seismic analyses of the original (IF) and retrofitted (DBIF) infilled structures are carried out using the OpenSEES platform [15]. Zero-length flexural- and shear-controlled elements are used to describe the inelastic response at the end-sections of RC frame members, with the internal part modelled with an elastic element, while a zero-length rotational spring is adopted for the beam-columns joints, reproducing shear failure prior to or after the achievement of yielding of the adjacent beams and columns [13]. An equivalent strut acting only in compression represents the inplane behaviour of masonry infills, where the peak response is evaluated as minimum prediction between diagonal compression, corner crushing, sliding shear and diagonal tension failure mechanisms $[19,20]$. Inherent damping equal to $\xi_{\mathrm{v}, \mathrm{F}}=5 \%$ is assumed for the $\mathrm{RC}$ framed structure, using mass and tangent stiffness proportional Rayleigh approach. Nonlinear fluid VDBs are modelled as nonlinear dashpots and linear springs [17], while truss elements with bilinear force-displacement law are considered for the HYDBs, with and without an inparallel or in-series combination with a gap-link working in parallel to a hook-link. Then, three sets of biaxial accelerograms, each consisting of seven earthquakes, are selected from the PEER database and scaled to three different intensity levels [16]. At the site of L'Aquila $\left(13.40^{\circ}\right.$ longitude and $42.35^{\circ}$ latitude), design response spectra of acceleration provided by NTC18 are evaluated for moderately-soft subsoil, considering a nominal life $\mathrm{V}_{\mathrm{N}}=50$ years and a functional class II (amplification factor, $\mathrm{C}_{U}=1.0$ ) resulting in a reference period $\mathrm{V}_{\mathrm{R}}=50$ years. These spectra are matched on average in a suitable range of vibration periods, with reference to $\mathrm{SDE}(\mathrm{PGA}=0.156 \mathrm{~g}), \mathrm{BDE}(\mathrm{PGA}=0.347 \mathrm{~g})$ and $\mathrm{MCE}(\mathrm{PGA}=0.407 \mathrm{~g})$.

The beneficial effects offered by the combination of HYDB1, ensuring structural safety (SS) at MCE, and VDB or HYDB2, calculated for immediate occupancy (IO) at SDE, are firstly investigated in Figures 7-9 with reference to the seismic performance of nonstructural elements. Specifically, maximum drift ratio of masonry infills $\alpha_{\Delta \mathrm{I}, \max }\left(=\Delta_{\mathrm{I}, \max } / \Delta_{\mathrm{I}, \mathrm{P}}\right.$, being $\Delta_{\mathrm{I}, \max }$ the mean of maximum drift demand at SDE and $\Delta_{\mathrm{I}, \mathrm{P}}$ the value corresponding to full cracking) 
is evaluated along the building height. As can be observed, the absence of openings in the infill walls along the $\mathrm{Y}$ direction (see Figure $5 \mathrm{~b}$ ) results in a significant reduction of $\alpha_{\Delta \mathrm{I} \text {,max }}$, whose values are less than those corresponding to the attainment of the peak lateral strength (i.e. $\alpha_{\Delta \mathrm{I}}=1$ ) for the IF structure, with a further slight improvement when DBIF structures are considered (Figures 7b, 8b,d and 9b).

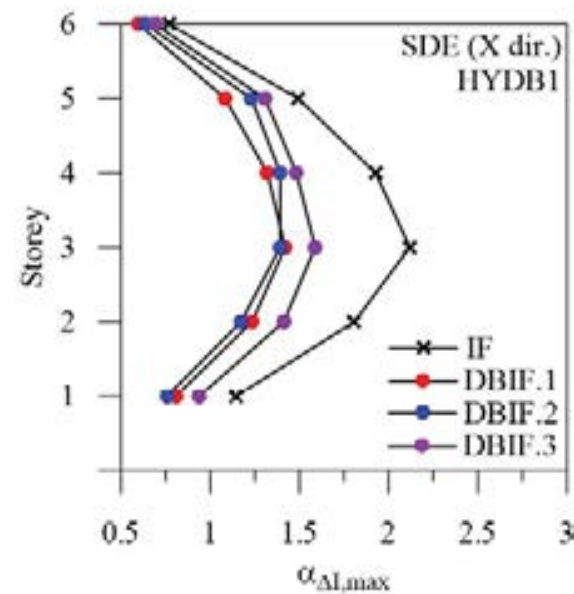

(a)

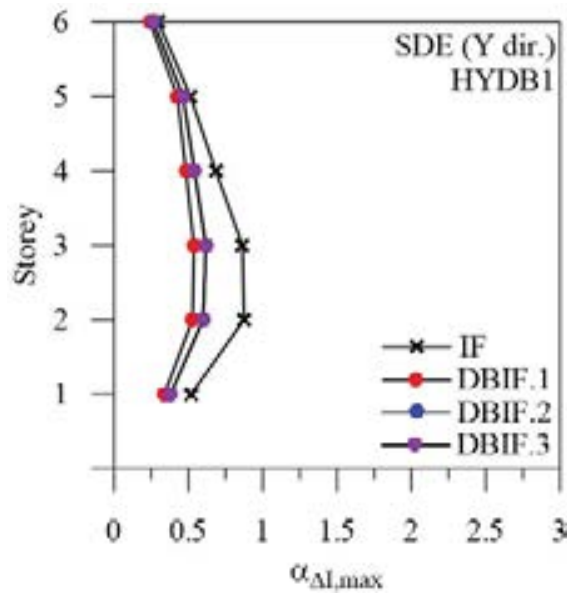

(b)

Figure 7. Maximum drift ratio of masonry infills for the original and retrofitted structures, at BDE: HYDB1.

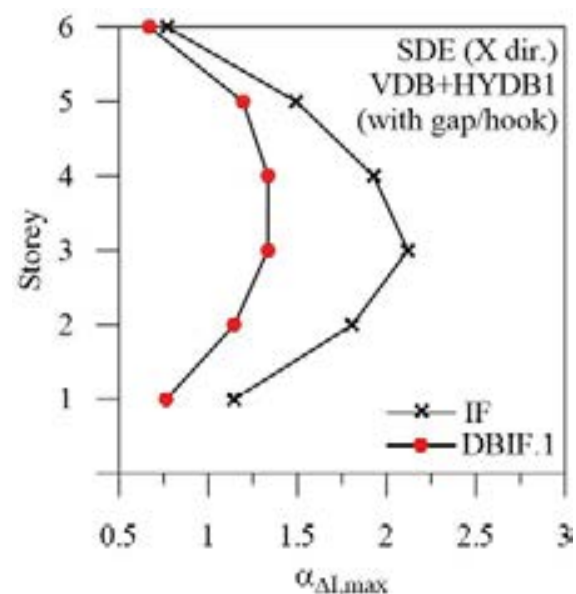

(a)

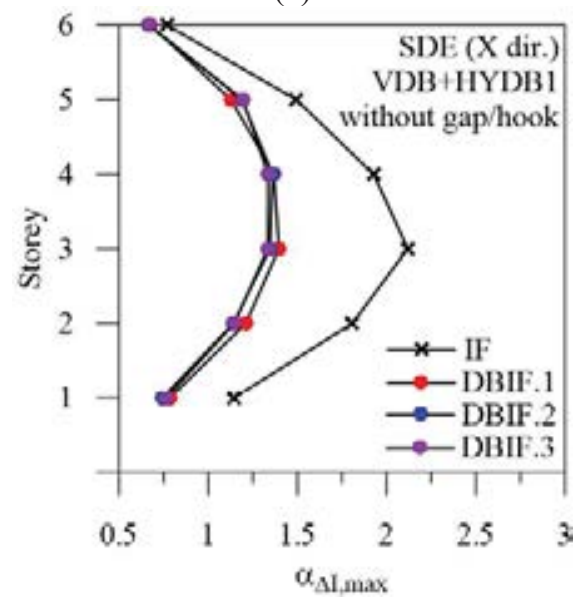

(c)

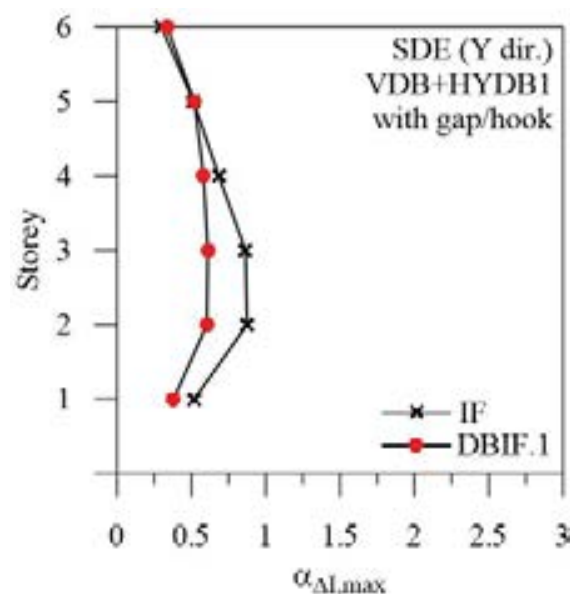

(b)

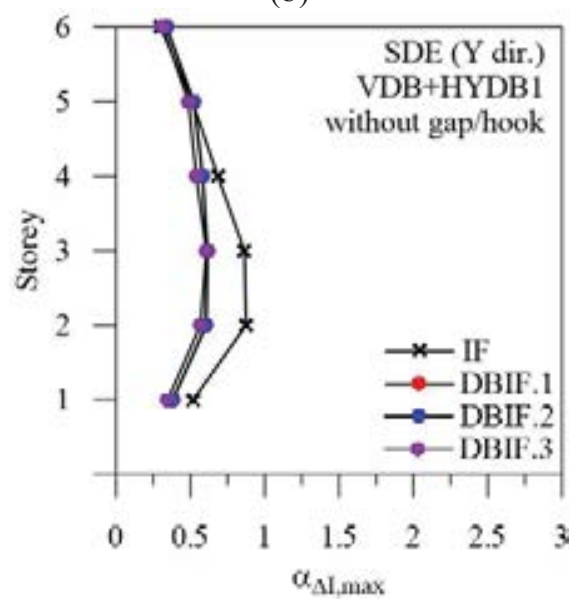

(d)

Figure 8. Maximum drift ratio of masonry infills for the original and retrofitted structures, at BDE: in-parallel HYDB1+VDB, with $(a, b)$ and without $(c, d)$ a gap-hook element in series with HYDB1. 
On the other hand, extensive damage of masonry infills is resulted for the original structure along the $\mathrm{X}$ direction, characterized by infill walls with different percentage of openings, attaining strength reduction at all levels the only exception being the roof (Figure 7a). With regard to the retrofitted structures, the IO condition at SDE is not reached at intermediate storeys for the HYDB1 solution (Figure 7a), where only target performance levels at MCE are checked. The in-parallel combination of HYDB1 and VDB, with (Figure 8a) and without (Figure 8c) a gap-hook element in series with HYDB1, has not produced a marked improvement of the response that has practically unchanged for all examined cases and beyond the damage threshold at the intermediate levels. On the other hand, a significant reduction of $\alpha_{\triangle I, \text { max }}$ is attained when the in-parallel combination of HYDB1 and HYDB2 is considered, with fulfilment of the IO condition for all values of $\Delta_{X} / \mathrm{h}$ at MCE (Figure 9a). Finally, results corresponding to the in-series combination of the HYDB1 and HYDB2 are plotted in Figures 9c,d. It should be noted that HYDBs deriving from the in-parallel combination (see Table 4) are adopted when in-series arrangement of HYDBs is considered along X (see Table 5). As can be observed, a different arrangement of the HYDBs impairs their performance, resulting in non-operational condition of the retrofitted structure at SDE (Figure 9c), while the response is essentially the same as that obtained for the in parallel arrangement when Y direction is considered (Figure 9d).

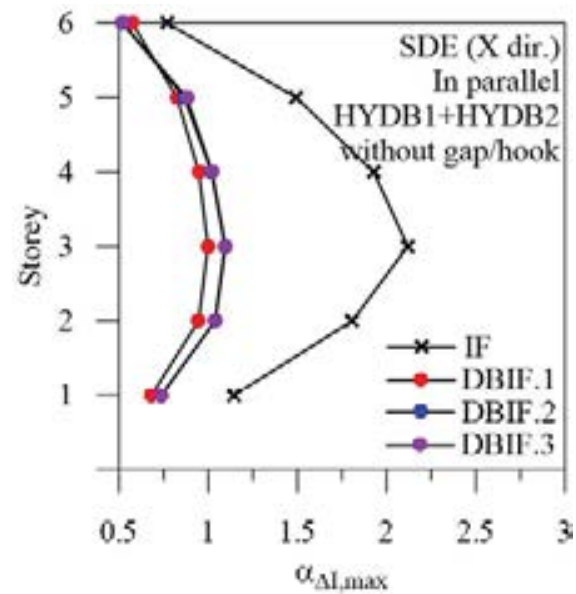

(a)

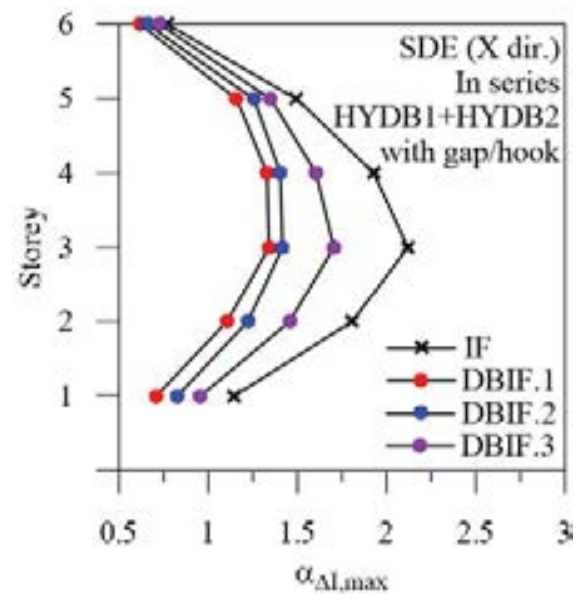

(c)

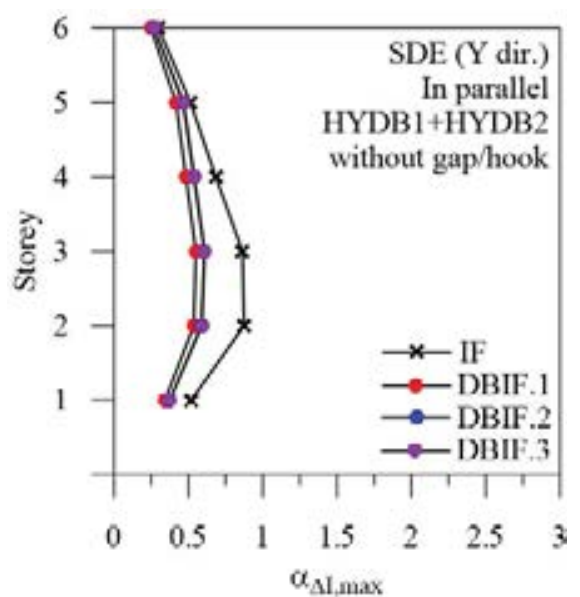

(b)

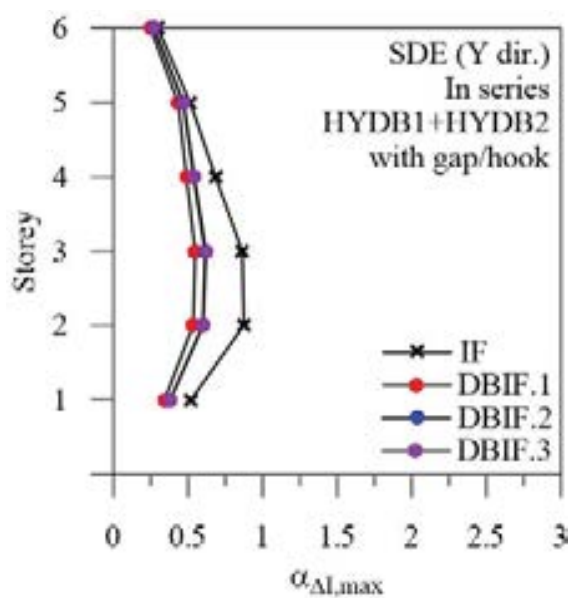

(d)

Figure 9. Maximum drift ratio of masonry infills for the original and retrofitted structures, at BDE: in-parallel $(a, b)$ and in-series (c, d) HYDB1+HYDB2. 
Afterwards, maximum drift ratio demand $\left((\Delta / \mathrm{h})_{\max }\right.$, with inter-storey displacement $\Delta_{\max }$ divided by the storey height $h$ ) at BDE is shown in Figure 10, only considering HYDB1 since results corresponding to the other four arrangements are practically identical to those obtained for this solution. The effectiveness of the HYDBs is confirmed in both directions, with similar response for all performance levels in the Y direction (Figure 10b). Moreover, target displacements (see dashed lines) are never exceeded in the Y direction, while DBIF.i structures ( $\mathrm{i}=1-3)$ are resulted more flexible compared to the design thresholds in the $\mathrm{X}$ direction.

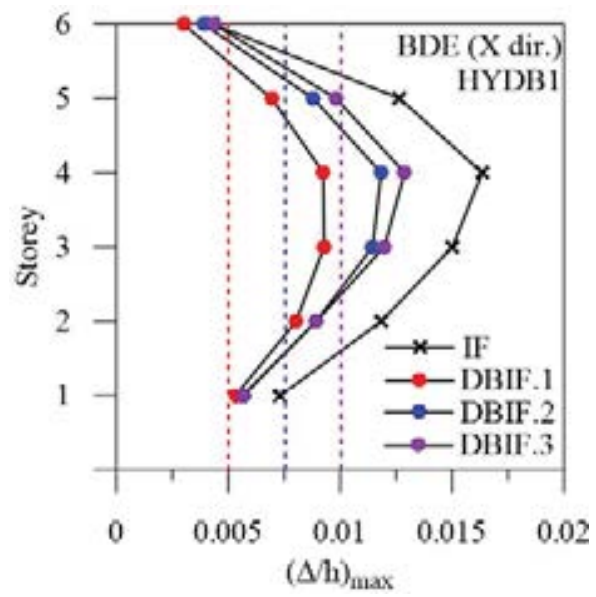

(a)

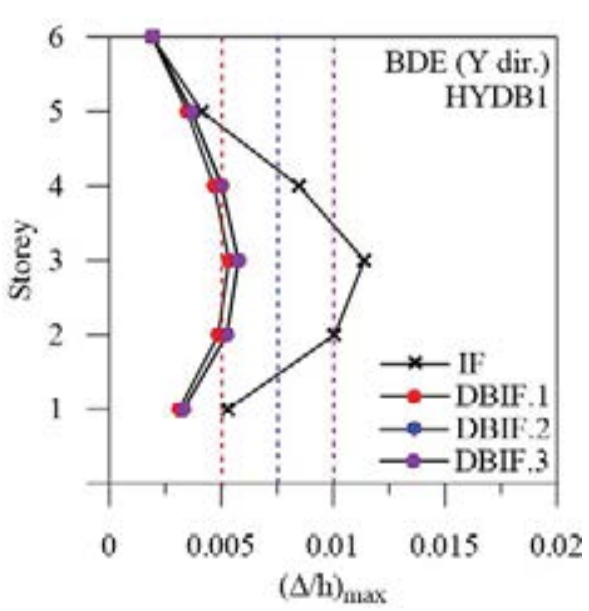

(b)

Figure 10. Maximum drift ratio for the original and retrofitted structures, at BDE: HYDB1.

Finally, maximum ductility demand $\left(\mu_{\mathrm{D} \text {,max }}\right)$ of the HYDBs at MCE are plotted in Figure 11 , referring to the in-elevation and in-plan distributions. For all performance levels, the ultimate value $\left(\mu_{\mathrm{D}, \mathrm{u}}=20\right)$ is never reached, so avoiding collapse of the dissipative devices, and a rather uniform demand is resulted along Y (Figure 11b). As a confirmation, decreasing values of $\mu_{\mathrm{D}, \max }$ are obtained for increasing values of target displacement.

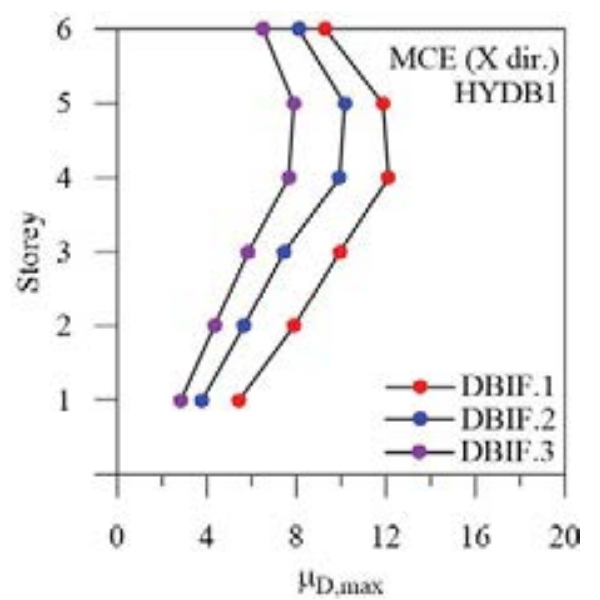

(a)

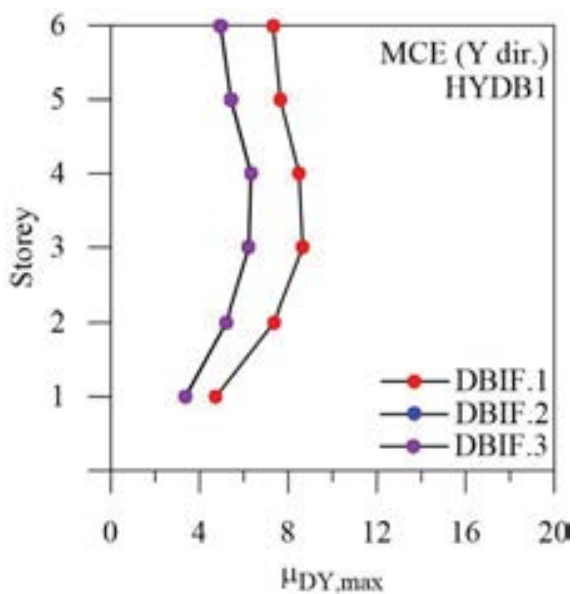

(b)

Figure 11. Maximum ductility demand of damped braces for the retrofitted structures, at MCE: HYDB1.

\section{CONCLUSIONS}

A displacement-based design procedure of damped braces is proposed for optimizing the seismic performance of buildings, by minimizing damage of both non-structural and structural 
elements at SDE and MCE, respectively. In order to quantify the enhanced seismic protection offered by the combination of HYDBs, designed at MCE, and HYDBs or VDBs, designed at SDE, comparison is made with a traditional solution consisting of HYDBs designed to guarantee the structural safety for severe ultimate limit state seismic events. Four alternative configurations are chosen for retrofitting the original building: in-parallel combination of HYDBs, at MCE, and VDBs, at SDE, with and without a gap-hook element in series with HYDBs; inparallel and in-series combinations of HYDBs, with and without a gap-hook element in parallel with HYDBs at SDE. The procedure is applied for the seismic retrofitting of an RC framed structure, located in L'Aquila and designed for a medium-risk seismic zone, representative of the residential housing stock built in Italy during the 1990s. By carrying out nonlinear dynamic multi-stripe analysis of the original and retrofitted infilled structures, under three intensity levels provided by Italian seismic code, the following conclusions can be drawn.

The absence of openings along the $\mathrm{Y}$ direction results in a significant reduction of damage in the infill walls of the original structure at SDE, differently from strength reduction affecting many infill walls, with different percentage of openings, along the $\mathrm{X}$ direction. As expected, HYDBs designed at MCE are not able to ensure the IO condition of the retrofitted structure because too high yielding forces do not allow their activation at SDE. The in-parallel combinations of the HYDBs and VDBs does not produce a marked reduction of damage at SDE for masonry infills at the intermediate storeys, whose drift remains beyond the damage threshold. The in-parallel combination of HYDBs, half designed at SDE and half at MCE, allows the fulfilment of the IO condition; the same HYDBs with an in-series arrangement impairs seismic response of masonry infills at SDE. The effectiveness of the HYDBs is confirmed in both directions at BDE, with target displacements not exceeded in the Y direction, while more flexibility compared to the design thresholds is highlighted in the $\mathrm{X}$ direction. Finally, maximum ductility demand of the HYDBs at MCE confirm that their ultimate value is never reached, so avoiding collapse of the dissipative devices.

\section{ACKNOWLEDGEMENTS}

The present work was financed by Re.L.U.I.S. (Italian network of university laboratories of earthquake engineering), in line to the Convenzione D.P.C.-Re.L.U.I.S. 2019-2021, WP15, Code Revisions for Isolation and Dissipation.

\section{REFERENCES}

[1] C. Christopoulos, A. Filiatrault, Principles of passive supplemental damping and seismic isolation. IUSS Press, Pavia, Italy, 2006.

[2] G. Terenzi, I. Costoli, S. Sorace, Activation control extension of a design method of fluid viscous dissipative bracing systems. Bulletin of Earthquake Engineering, 18, 4017 4038, 2020.

[3] Gandelli E, Taras A, Distl J, Quaglini V. Seismic retrofit of hospitals by means of hysteretic braces: influence on acceleration-sensitive non-structural components. Frontiers in Built Environment 2019; 5:10.3389/fbuil.2019.00100.

[4] R. Aghlara, M. Md. Tahir, A passive metallic damper with replaceable steel bar components for earthquake protection of structures. Engineering Structures, 159, 85-197, 2018.

[5] T. Shiomi, K. Fujita, M. Tsuji, I. Takewaki, Dual hysteretic damper system effective for broader class of earthquake ground motions. International Journal of Earthquake and Impact Engineering, 2(3): 175-202, 2018. 
[6] S. Hashizume, I. Takewaki, Hysteretic-viscous hybrid damper system for long-period pulse-type earthquake ground motions of large amplitude. Frontiers in Built Environment, 6, article 62, 2020.

[7] E. Gandelli, S. Chernyshov, J. Distl, P. Dubini, F. Weber, A. Taras, Novel adaptive hysteretic damper for enhanced seismic protection of braced buildings. Soil Dynamics and Earthquake Engineering, doi.org/10.1016/j.soildyn.2020.106522

[8] F. Mazza, A. Vulcano, Design of hysteretic damped braces to improve the seismic performance of steel and RC framed structures. Ingegneria Sismica, 31(1), 5-16, 2014.

[9] F. Mazza, Seismic vulnerability and retrofitting by damped braces of fire-damaged RC framed buildings. Engineering Structures, 101, 179-192, 2015.

[10] F. Mazza, Nonlinear seismic analysis of unsymmetric-plan structures retrofitted by hysteretic damped braces. Bulletin of Earthquake Engineering, 14(4), 1311-1331, 2016.

[11] F. Mazza, A simplified retrofitting method based on seismic damage of a SDOF system equivalent to a damped braced building. Engineering Structures, 200, 109712, 2019.

[12] F. Mazza, A plastic-damage hysteretic model to reproduce strength stiffness degradation. Bulletin of Earthquake Engineering, 17(6), 2787-2819, 2019.

[13] P. Ricci, V. Manfredi, F. Noto, M. Terrenzi, M.T. De Risi, M. Di Domenico, G. Camata, P. Franchin, A. Masi, F. Mollaioli, E. Spacone, G.M. Verderame, RINTC-E: towards seismic risk assessment of existing residential reinforced concrete buildings in Italy. Procs. of the $8^{\text {th }}$ ECCOMAS Thematic Conference on Computational Methods in Structural Dynamics and Earthquake Engineering COMPDYN 2019, Crete, Greece, 24-26 June 2019.

[14] NTC18, Norme tecniche per le costruzioni. DM 17-01-2018, Italian Ministry of Infrastructures and Transports, Rome, Italy, 2018.

[15] F. McKenna, G.L. Fenves, M.H. Scott, Open system for earthquake engineering simulation. University of California, Berkeley, CA, 2000.

[16] I. Iervolino, A. Spillatura, P. Bazzurro, Seismic structural reliability of code-conforming Italian buildings. Journal of Earthquake Engineering, 22, 5-27, 2018.

[17] F. Mazza, Dissipative steel exoskeletons for the seismic control of reinforced concrete framed buildings. Structural Control and Health Monitoring, 28(3), e2683. DOI: 10.1002/stc.2683, 2020.

[18] A. Sepehri, T. Taghikhany, S.M.R. Ahmadi Namin, Seismic design and assessment of structures with viscous dampers at limit state levels: Focus on probability of damage in devices. The Structural Design of Tall and Special Buildings, 28, e1569, 2018.

[19] DM86, Norme tecniche relative alle costruzioni antisismiche. D.M. 24-01-1986, Italian Ministry of Public Works, Rome, Italy, 1986.

[20] F. Mazza, In- plane-out- of- plane non- linear model of masonry infills in the seismic analysis of r.c.- framed buildings. Earthquake Engineering \& Structural Dynamics, 48(4), 432-453, 2019.

[21] F. Mazza, A. Donnici, In-plane and out-of-plane seismic damage of masonry infills in existing RC structures: the case study of De Gasperi-Battaglia school in Norcia. Bulletin of Earthquake Engineering, 19, 345-376, 2021. 